\title{
Research Scheme for Vegetable Price Transmission and the Early Warning based on Associations with Non-target Areas
}

\author{
Fantao Kong ${ }^{1, \text { a }}$, Jianzhai $\mathrm{Wu}^{1, \mathrm{~b}}$,Jianhua Zhang ${ }^{1, \mathrm{c}}$, Shuqing $\mathrm{Han}^{1, \mathrm{~d}}$ and Huishang \\ $\mathrm{Li}^{1, \mathrm{e}}$ \\ ${ }^{1}$ Agricultural Information Institute, Chinese Academy of Agricultural Sciences; Key Laboratory of \\ Agri-information Service Technology, Ministry of Agriculture, Beijing 100081, China \\ akongfantao@caas.cn, bwujianzhai@caas.cn, czhangjianhua@caas.cn, dhanshuqing@caas.cn, \\ elihuishang@cas.cn
}

Keywords: vegetable; price transmission; early warning based on associations with non-target areas; research scheme.

\begin{abstract}
A clear grasp of vegetable price transmission mechanism and the ability to make early warning for vegetable price are important for guaranteeing the effective supply and stabilizing the market price of vegetables. Therefore, it is of great significance to conduct a research on vegetable price transmission and the early warning considering the associations with non-target areas. The implementation plan for the research was expounded from the research methods, technical route, key technologies and innovations.
\end{abstract}

\section{Introduction}

Vegetable price is an important part of people's livelihood. In recent years, the coexistence of expensive price and difficult sales of vegetables caused by the unbalance of supply and demand, the radical change of vegetable price and large regional disparity in vegetables price have not only harmed the immediate interests of vegetable growers and consumers, but also wasted valuable natural resources. Against the background of "the four modernizations", informatization is directing the progress of and providing a strong technical support for modernization. Such information technologies as big data, internet of things and cloud computing offer new ideas and methods for solving the problems concerning spatial-temporal transmission of vegetable price and the early warning based on associations with non-target areas. On the basis of allowing full play to the role of market mechanism, the solving of these two problems cannot only promote vegetable production and ensure the basic stability of market supply and price, but also facilitate the sustained and sound growth of national economy. Therefore, this study put forward the scheme for studying the transmission mechanism of vegetable price and its early warning based on associations with non-target areas.

\section{Research methods}

The following are methods for studying vegetable price transmission and remote early warning. Survey Method

In terms of the vegetable variety, this study selected Chinese cabbage, radish, cucumber, tomato, cowpea and garlic as the research object. The research area covered 12 provinces or cities, including Beijing, Shanghai, Tianjin, Heilongjiang, Hebei, Shandong, Shaanxi, Sichuan, Hunan, Fujian, Guangdong and Henan. We improved 54 existing vegetable information collecting points, and established 85 new ones. Among the 139 information collecting points, 59 provide market information and 80 production information. In order to complete data collection in these vegetable information collecting points, it is of great urgency to conduct survey. Field survey is one of the two survey forms, which is conducted, in principle, once every year in 12 provinces or cities. The other form is monthly routine telephone interview. The survey frequency can be raised in the case of special objects or special events. 
Econometric analysis

This study used many economic models and statistical methods. For example, by calculating correlation coefficient and conducting augmented Dickey-Fuller test (ADF, a test for unit root), cointegration test and Granger causality test, the relationship and route of spatial-temporal transmission of vegetable price were explored. Finite distributed-lag model, seasonal structural vector autoregressive model and pulse response function were adopted to study the velocity, strength and sustainability of price transmission. Besides, the kernel density estimation method in nonparametric statistics and variance decomposition method of pulse response function were also used to study vegetable price transmission and the early warning based on associations with non-target areas.

Computer simulation

The big data-related technologies were employed to analyze and process multi-source and multi-scale data of vegetable price. Vegetable price information management system was constructed with database technology. Module design was performed with component technology, ArcGIS technology and visualization technology, thus achieving the simulation and three-dimensional visualization for vegetable price transmission and early warning.

Other Methods

This study also used some other research methods like literature review and expert consultation. Specifically, literature review enabled us to track the research progress of vegetable price transmission mechanism, obtain relevant data, information and materials and learn about related theories, techniques and research methods. As for some uncertain factors arising in the research process and some key theoretical methods and technical application problems, we consulted the experts in some fields and took their advice.

\section{Technical route}

The following is the general roadmap of this article. Firstly, based on literature review and surveys, the pattern and influencing factors of vegetable price fluctuations were determined; the vegetable price information management system was established, and the China's vegetable price transmission mechanism was revealed preliminarily. Secondly, a comprehensive model set for vegetable price spatial-temporal transmission was built from the perspective of space, time and variety, to quantify the evolution rule of vegetable price. Thirdly, the early warning for vegetable price based on associations with non-target areas was studied, with the spatial-temporal transmission taken into consideration; the warning limit in the target area for early warning was clearly divided; the "source area of transmission" and "critical threshold" were sought for and modeling was performed for the early warning based on associations with non-target areas. Lastly, we conducted a simulation on the vegetable price transmission. Using a secondary R\&D platform of ArcGIS, we realized the deep coupling of the spatial-temporal transmission model and early warning model of vegetable price, scenario simulation and three-dimensional visualization; some policy proposals were further proposed for China's vegetable production and marketing. 


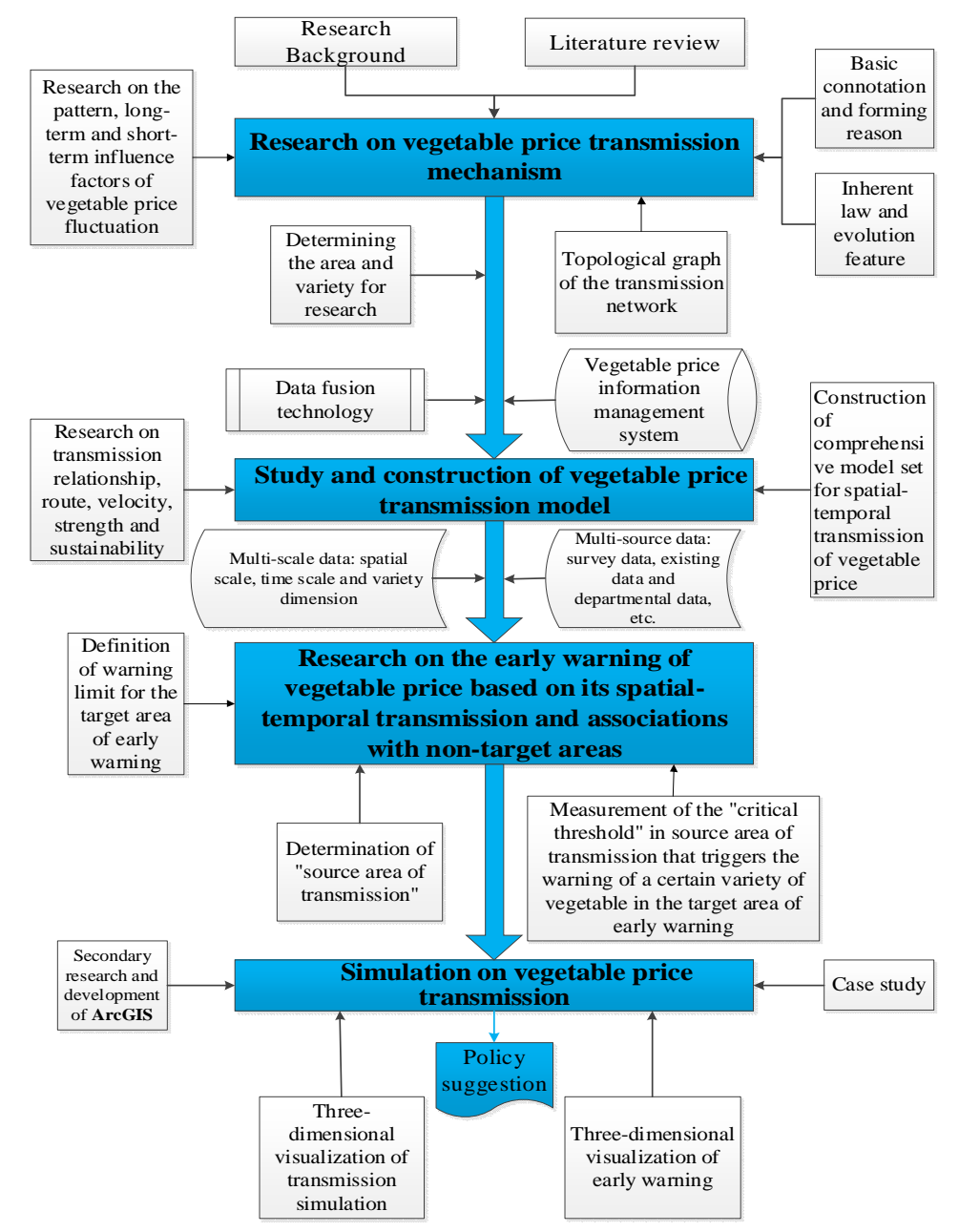

Fig 1 Technical Route

\section{Key technologies}

In the execution process, a series of problems may emerge, e.g. unstable information collection for vegetable price, how to construct the seasonal structural vector autoregressive model, how to select an early warning model and define the warning limit, how to integrate multi-source and multi-scale price data, and how to simulate the spatial-temporal transmission. To stick to the research direction and smooth away difficulties, the following key technologies were adopted.

Control Technology for Objects under Long-term Located Monitoring

The variation and control of research objects has always been one of the thorny issues in the field of management science, and this study is no exception. The 54 existing collecting points for vegetable market information have become mature and stable after nearly three years' operation. The 5 newly added vegetable information collecting points in Heilongjiang Province are basically stable as they target market price data. In the remaining 80 newly added collecting points targeting vegetable production information, large-scale vegetable growers probably leave the planting industry, due to labor mobility, drive of industry benefits and adjustment of planting structure. This causes difficulty in long-term located monitoring and follow-up investigation. To overcome this difficulty, this study employed the following countermeasures. Firstly, the collecting points for vegetable production information should be arranged in the 580 key counties for vegetable planting designated by the Ministry of Agriculture. It is because these key counties are important base for vegetable supply and production in China and have long been engaged in vegetable production. Secondly, since we undertake the tasks of the "panel for vegetable market monitoring and early warning of the Ministry of 
Agriculture", it is easier to carry out a preliminary investigation before the screening of information collecting points. The screening criteria include each household's history of vegetable planting (over 3 years), planting scale (with a planting area ranking among the first 15 in the village), technical know-how, management skills and harmonious neighbor relationship. One village should be chosen in each province and then 5-8 large-scale growers should be screened in the village as the vegetable production information collecting points. Thirdly, technical maturation and integrated innovation should be conducted on the "portable holographic market information collector for agricultural products". The means of information collection was improved by making the "collector" better fit the collection of vegetable production information.

Techniques for Evaluating the Seasonal Effect of Spatial-temporal Transmission of Vegetable Price Despite the existence of numerous transmission models, how to scientifically choose, revise and improve these models, especially the seasonal structural vector autoregressive model, to construct a systematic research method for vegetable price transmission still has some difficulty. This study used correlation analysis, long-run equilibrium relation test, error correction model and other techniques to analyze the relationships in the spatial-temporal transmission of vegetable price. Granger causality test was applied to analyze the transmission routes. Finite distributed-lag model, structural vector autoregressive model and pulse response function were applied to analyze the velocity, strength and sustainability of the transmission. Based on these analyses, a methodology for the research of spatial-temporal transmission of vegetable price was formed. In the construction of seasonal structural vector autoregressive model, the dummy variable to reflect seasonal association and the cross influence of dummy variable and price are added. In the calculation of pulse influence function, the cross influence of virtual variable and price is included, so as to obtain the differential response of price impact at different season and realize the improvement and revision of structural vector autoregressive model. Careful consideration should be given to the setting of seasonal dummy variable and the including of the cross influence of dummy variable and price.

Early Warning Technique for Vegetable Price based on Its Spatial-temporal Transmission and Associations with Non-target Areas

The early warning for vegetable price based on its spatial-temporal transmission and associations with non-target areas is not only the innovation of this article but also a technical problem that needs to be solved. This study used kernel density estimation to determine the warning limit for a certain variety of vegetables in the target area. The variance decomposition method of pulse response function was used to reveal the dynamic changes in the contribution of "source area of transmission" to the price response of target area. Thus the "source area of transmission" responsible for the price fluctuation of a certain variety of vegetables can be identified. Through regional correlation analysis and according to warning limits set for the target area, the "critical threshold" for price changes in the "source area of transmission" was estimated. Then the warning condition can be judged based on the critical threshold. However, further exploration is needed for the definition of warning limit and warning condition, the determination of contribution degree of an associated area, and the triggering of the "critical threshold" of "source area of transmission".

Technology for Fusing the Multi-source and Multi-scale Data of Vegetable Price

Besides the existing vegetable price data, which have huge quantity, complicated type and multiple sources and scales, there are also new long-term located monitoring data. So how to scientifically store, manage and apply these data is also a technical challenge. This study aims to develop a vegetable price information management system to carry out intelligent management. Such functions as fast data input, accurate output, convenient call and brief analysis should be realized for the system. With such a management system, the multi-source and multi-scale vegetable price data can be fused preliminarily. Simulation and Display Technologies for Spatial-temporal Transmission and Early Warning There are also technical difficulties in the simulation of spatial-temporal transmission of vegetable price and its early warning based on the association with non-target areas. This study explored the simulation techniques for spatial-temporal transmission of vegetable price based on ArcGIS, realizing the modularization for transmission simulation in the GIS platform. Meanwhile, research was performed 
on the three-dimensional visualization of vegetable price's spatial-temporal transmission and early warning model. In the scenario simulation for spatial-temporal transmission and case study on early warning, the inquiry, monitoring and early warning of vegetable price have been realized based on ArcGIS, with a three-dimensional display of the results.

\section{Innovations}

The features and innovations of this research lie in the following four aspects:

Systematically revealing the Vegetable Price Transmission Mechanism from the Perspective of Time and Space

There are numerous literatures on price transmission. But few conducted a systematic research by building seasonal factors-based spatial-temporal transmission model for vegetable price with multi-source and multi-scale data, to explore the early warning based on spatial-temporal transmission and associations with non-target areas, and to realize a simulation and three-dimensional visualization. The perspectives of space, time, variety, industry chain (production, wholesale and retail) and associations with non-target areas are integrated in this article. A series of studies were carried out by quantifying the seasonal factors in vegetable production and sale and utilizing data fusion, model updating, ArcGIS and monitoring and early warning technologies. We analyzed the relationship, route, velocity, strength and sustainability of vegetable price transmission, and quantified the price transmission relationship between regions and between various links of the industry chain. Thus we further revealed the inherent law and evolution mechanism in the spatial-temporal transmission of vegetable price. Therefore, theoretical innovation is one of the innovations of this work.

Innovatively Adding the Seasonal Factors in the Spatial-temporal Transmission Model of Vegetable Price

A quantitative research and judgment was made on the relationship and route in the spatial-temporal transmission of vegetable price by calculating correlation coefficient and carrying out ADF test, cointegration test and Granger causality test. In the research on the velocity, strength and sustainability of the spatial-temporal transmission, such techniques as finite distributed-lag model, structural vector autoregressive model and pulse response function were adopted. Meanwhile, the seasonal factors in vegetable production were also considered in the construction of seasonal structural vector autoregressive model. Thus the effects of seasonal factors in the spatial-temporal transmission of price can be identified. This study added dummy variable and its cross influence with price to the structural vector autoregressive model and included this cross influence in the computation of pulse response function. In this way, different responses for the price impact in different seasons were obtained while the structural vector autoregressive model was improved. In other words, this work innovatively put forward a spatial-temporal transmission model of vegetable price considering the seasonal factors. It means a technical innovation.

Putting Forward an Early Warning Method for Vegetable Price based on its Spatial-temporal Transmission and Associations with Non-target Areas

The existing research on early warning of vegetable price generally focuses on the "local" events, but rarely concerns whether the relevant indexes in "non-target area" exceeds the critical value. This study took into consideration the variation of relevant indexes in non-target areas in the research and judgement of early warning. The specific research procedure is as follows. First, the established spatial-temporal transmission model of vegetable price which considers seasonal factors was used to assess the effect of seasonal factors on the transmission and reveal the spatial distribution and time lag of the transmission. Second, the nonparametric kernel density estimation was used to define the scope of warning for a certain variety of vegetable in the target area of early warning". Third, using the variance decomposition method of pulse response function, we can grasp the dynamic changes of the contribution of "source area of transmission" to the price response in the target area. Then the "source area of transmission" on the provincial or regional scale which affects the price fluctuation ofa vegetable can be identified. At last, the "source area of transmission" that triggers the warning and its 
critical threshold were determined through regional association analysis based on the defined warning limit of the target area. In brief, this study calculated the degree of association between "the target area of early warning" and "source area of transmission" in vegetable production and sale; the critical threshold for relevant indexes of "the source area of transmission" was determined; an innovation wad made on the inter-regional early warning technique for vegetable price. Accordingly, an early warning method for vegetable price based on spatial-temporal transmission and associations with non-target areas was proposed. It means an innovation in methodology.

Realizing the Fusion of Vegetable Price Data and Visualization of Transmission Simulation

Firstly, considering the multiple attributes (e.g. data source, spatial scale, time scale, industry chain, vegetable variety, and data structure) of vegetable price data, this study developed the "vegetable price information management system" for intelligent management. Fast data input, accurate output, convenient calling, and brief analysis were realized for this system. Meanwhile, big data technology was used to analyze the different contribution and differential effects of multi-source and multi-scale data in vegetable price transmission. Thus a data support is provided for the spatial-temporal transmission model and early warning model of vegetable price, and the data fusion technology for the multi-source and multi-scale vegetable price has already taken shape. Secondly, taking advantage of the secondary research and development platform of ArcGIS and the modern information technologies like component-based development, embedded development technology, we made some innovations on the module development and application. By the deep coupling of transmission model and ArcGIS, we realized the scenario simulation and the three-dimensional visualization of the spatial-temporal transmission of vegetable price. Thus the evolution characteristics and pattern are embodied.

\section{Conclusion}

This research made comprehensive use of relevant knowledge in the field of economics, geography, statistics and information science, showing an obvious interdisciplinary feature.

\section{Acknowledgements}

Funding Project: Research on Spatio-temporal Transmission Mechanism and Early Warning of Multi-region Correlation in Vegetable Price, National Natural Science Foundation of China, Grant No. 71573263; Corresponding author: Huishang Li)

\section{References}

1. Li zhemin, Li Qiong, Li Shang, Liu Yun. dry green pepper pricing report and profit distribution [J] Agricultural Outlook, 2008, (5) .

2. Xu Qiao, Zhang Zhiqiang, Wang Qiong,Wang Qi Li. Dong Xiaoxia survey tomato pricing and profit distribution [J] Agricultural Outlook, 2008, (5)

3. Fan Runmei, Pang Xiaopeng. Wang Zhengnan. Vegetable market wholesale and retail price and price transmission mechanism - Taking Beijing as an example [J] Commercial Research, 2007

4. Rui Li. CPI full transfer relation with PPI empirical analysis [J] modern commercial, 2009, (26) .doi:. 10.3969

5. Zhao yousen, Zhao Anping. Beijing vegetable wholesale market changes [J]. Chinese Food and Nutrition, 2010, (4) 